\title{
Gene Regulation Process
}

National Cancer Institute

\section{Source}

National Cancer Institute. Gene Regulation Process. NCI Thesaurus. Code C21050.

Any of the processes by which nuclear, cytoplasmic, or intercellular factors influence the differential control of gene expression at the level of transcription or translation. 